\title{
Development of Vehicle Lane Changing Model in Approaching the U-Turn Facility Road Segment
}

\author{
Mohd Shafie Nemmang ${ }^{1}$ and Raha Rahman ${ }^{2}$ \\ 1. Faculty of Civil and Environmental Engineering, Universiti Tun Hussein Onn Malaysia, 86400 Batu Pahat, Johor, Malaysia; \\ 2. Department of Infrastructure and Geomatic Engineering, Faculty of Civil and Environmental Engineering, Universiti Tun Hussein \\ Onn Malaysia, 86400 Batu Pahat, Johor, Malaysia
}

\begin{abstract}
Accidents are in rising mode and became the main problem all over the world especially in Malaysia as the reasons including the condition of the road, driver's reaction and the road environment. Actually, those condition also factors to execute the lane changing which experienced by all drivers such as in U-turn road segment. In approaching U-turn segment, drivers needed to make a decision whenever any disruption in front of them such as merging vehicle because they have their own perspective and desire. For that purpose, this research is focusing on the reaction of the driver in approaching the U-turn facility road segment especially in speed $(V)$, reaction time $(R T)$ and distance where from those parameters and their relationships, the statistical model was developed and used in estimating the safe distances to execute the lane changing from the merging vehicle. The data were taken from the field and driving simulator to come out with the raw data. The field data were from video recording that has been used to simulate the driving simulator. Therefore, through the relationship between the $R T$, speed $(V)$ and distance of the subject vehicle to the merging vehicle, the statistical model has been developed with the equation $D_{A M V U T}=(13.448+1.410 R T-0.075 \mathrm{~V})$.
\end{abstract}

Key words: Lane changing, merging, U-turn.

\section{Introduction}

Rahman [1] described that Malaysia consists of thirteen states and three federal territories and has a total landmass of $329,847 \mathrm{~m}^{2}$ separated by the South China Sea into two similarly sized regions, Peninsular Malaysia and Malaysian Borneo. The capital city is Kuala Lumpur. Rahman [1] also stated that in year 2010, the population was exceeded from 27.5 million and now in 2015, it has grown into 30 million, with over 20 million living on the peninsular. A lot of studies have been done about the lane changing whether for roundabout, traffic light, junction and road curve/design for heavy and light vehicle. Unfortunately, there are no researches that have been done for lane changing in U-turn. However, Nemmang et al. [2] find out that driver tend to speed at the U-turn area which is more than $40 \%$ higher than

Corresponding author: Mohd Shafie Nemmang, postgraduate student; research field: traffic engineering. E-mail: mohdshafienemmang@gmail.com. the speed limit. Therefore, this research developed a vehicle lane changing model in approaching at U-turn facility road segment. It requires the performance of vehicle movement by considering the traffic engineering parameters which related to Malaysian driver's reaction such as reaction time, speed and distance in executing the lane changing. The establishment of suitable U-turn and appropriate condition is needed in order to achieve the entire objectives. The reasonable method to perform the data is by using driving simulator where this technique can allow data collection to be reliable and well-organized. Leitão et al. [3] stated that driving simulator can give a real scenario for the driver that can make the model valid to use. In addition, this research concerns on the U-turn road segment situation due to the study implementation. Therefore, this research provided knowledge, understandings and new findings in the field of traffic engineering. It cannot be argued that this research is very important especially in guiding the 
drivers that will eventually lead in reduction in number of accidents.

\section{Literature Review}

Md Dia et al. [4], and Md Dia et al. [5] claimed that there is a "lack of knowledge" of corresponding methods for the traffic performance at the intersection and of Malaysian driver behaviour. Many researchers have defined the lane changing such as Zhao et al. [6] defined lane change as a driving manoeuvre that moves a vehicle from one lane to another lane where both lanes have the same direction of travel. Moridpour et al. [7] asserted that lane changing models need the accuracy of essential components of microscopic traffic simulation in develop lane changing model. It is assumed that a driver makes consideration between expected own advantage and the disadvantage when a lane change is considered. Moreover, Keyvan-Ekbatani et al. [8] categorized the lane change decision process on freeways using microscopic traffic simulation. They asked driver to drive on a freeway with a camera equipped vehicle and asked the driver to comment on lane and speed preferred. Zheng et al. [9] studied the effects of lane changing on the immediate follower by measuring the induced transient behaviour and the change of driver behaviour because of immediate follower. Lv et al. [10] studied lane changing behaviour on three lane highways using simulation. The optimal velocity model obtained continuous position and velocity in space and time. Therefore, this research focuses on developing the lane changing model using the driving simulator to come out with the raw data from the driver's real reaction and behaviour.

\section{Participants}

In this research, the sample taken was 100 drivers and that group of people must be 18 years old or above. Drivers' characteristics show that the lowest age is 18 and the highest age is 35 years old. The average age is 24 years old. For the driver characteristics, from total 100 drivers, 62 are men and 32 women. All the drivers are free from distraction such as telephone because it may affect their driving process. Benedetto et al. [11] studied the effects of mobile telephone tasks on driving performance where they used two methods which are driving simulation and video recording in determining the results where reaction time generally increases when using a mobile equipment but decreasing the driving performances. Drivers were taken from the student, workers and the people around. The most important thing is that they have a valid Malaysian driving license. Driving license is an important criterion in order to make the research and the data output is valid because they are already familiar with the rule and have some experiences in driving. All the sample was invited from the poster promotion, social media and verbal invitation.

\section{Result and Analysis}

\subsection{Data Boxplot}

In descriptive statistics, a boxplot is a convenient way of graphically depicting groups of numerical data through their quartiles. Boxplots may also have lines extending vertically from the boxes indicating variability outside the upper and lower quartiles. Outliers may be plotted as individual points. In this research, all the datasets ascertained in developing the model which are distances $(D)$, speed $(V)$ and reaction time $(R T)$ are in normal datasets as shown in Figs. 1-3. All the outliers were removed from the data in analyzing process. This research removed only 5 data from the total data that has been used in developing the statistical model. That means, there are only $6.25 \%$ outliers in the data. Therefore, the result of the boxplot for every dataset are:

\subsection{Descriptive Statistic}

After there are no outliers, the data need to be defined through the descriptive statistic in order to define the mean, median, maximum and minimum value of the data. It is important to know the limitation of the minimum and maximum for each data variables 


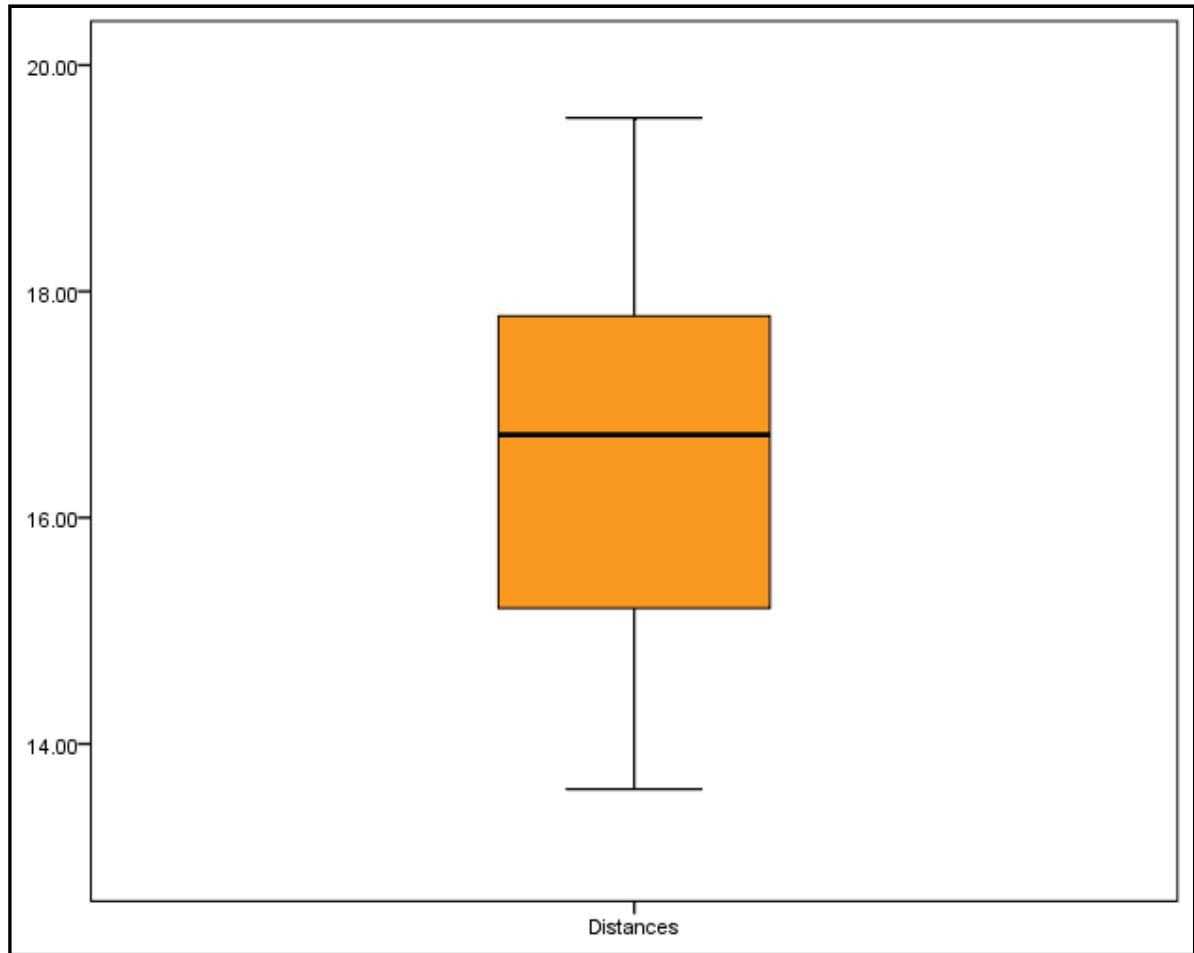

Fig. 1 Distance data boxplot.

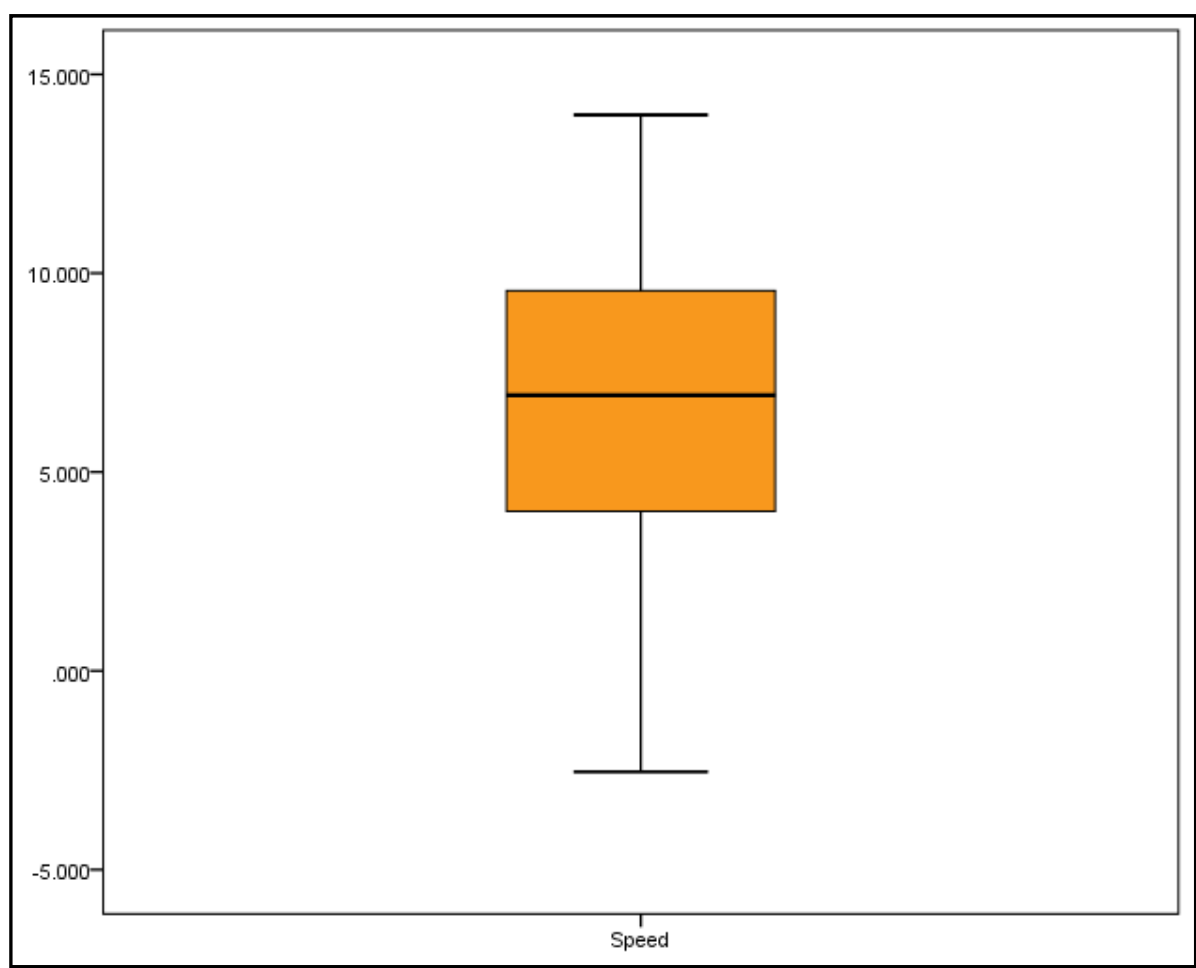

Fig. 2 Speed data boxplot. 


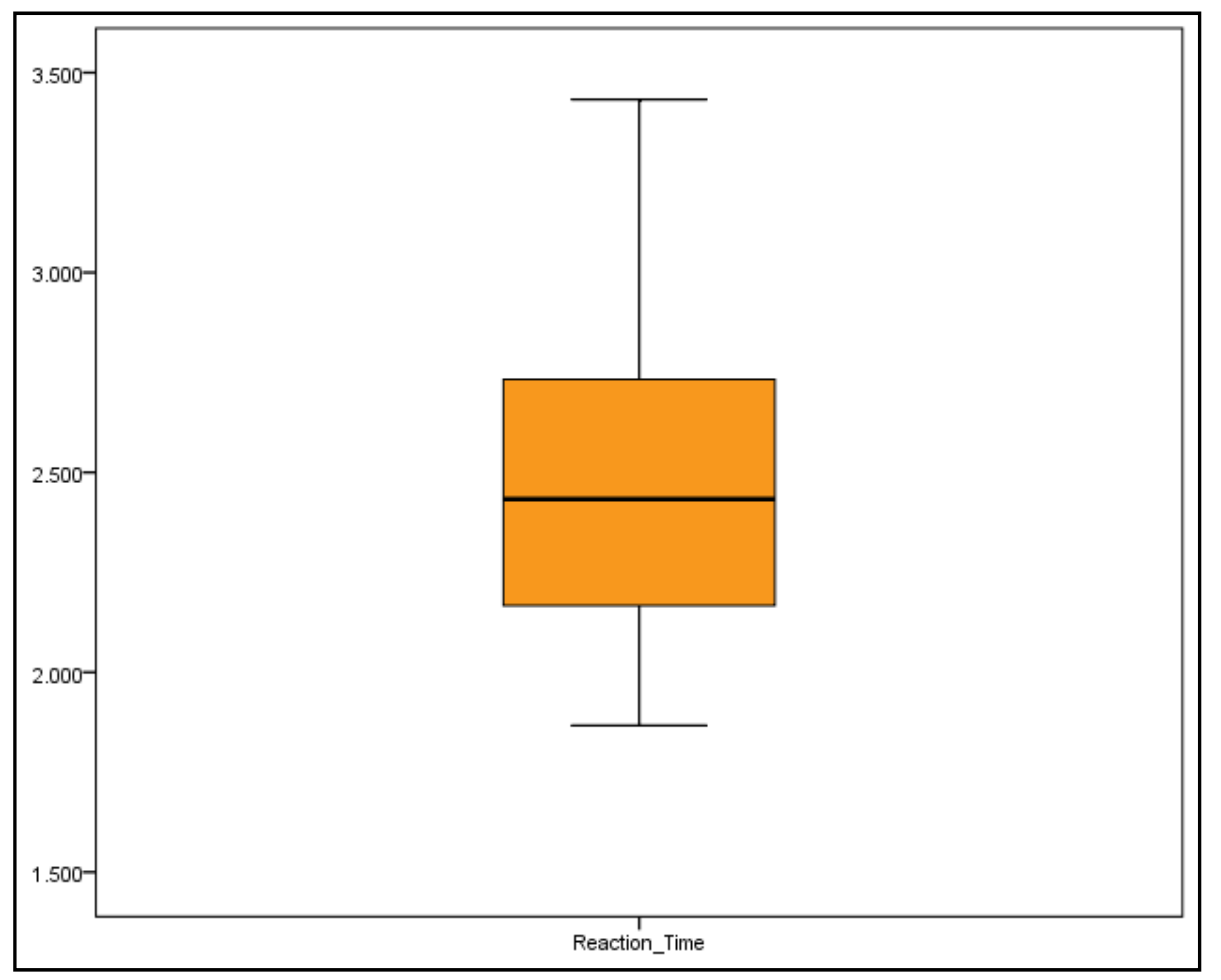

Fig. 3 RT data boxplot.

to ensure that the data are valid to be used in developing the model. The data need to be screened thoroughly in order to know the exact range of each data variable. Therefore, the results of the descriptive analysis for every dataset are shown in Table 1.

\subsection{Model Development}

$$
D_{\text {AMVUT }}=(13.448+1.410 R T-0.075 \mathrm{~V})
$$

where:

$D_{A M V U T}=$ distance before changing lane in approaching merging vehicle at U-turn facility road segment;

$R T=$ reaction time of the subject vehicle due to changing lane;

$V=$ speed differences of the subject vehicle due to changing lane.

\subsection{Regression Analysis for Final Model in Estimating $D_{\text {AMVUT }}$}

The ANOVA (analysis of variance) outputs are shown in Table 2. In the ANOVA statistical analysis, the model useful or useless depends on the
$P$-valuewhich are the values that should be less than significance level 0.05 . Therefore, the hypothesis statement is stated as follows:

- $H_{0}=$ the $D_{A M V U T}$ model cannot be used for predicting;

- $H_{1}=$ the $D_{A M V U T}$ model can be used for predicting. Variance analysis came out with the $P$-value where the value is less than the $\alpha$-level of 0.05 , where $\mathrm{F}(2,77)$ $=6.240, p=0.003$. Therefore, $H_{1}$ must be accepted and $H_{0}$ must be rejected. Hence, the regression model that has been developed is significant and thus can explain the $D_{A M V U T}$ model.

Moreover, Table 3 stated that reaction time $(R T)$ and speed $(V)$ were considered as independent variables to calculate the $D_{A M V U T}$ where the $P$-value is less than 0.05 . Therefore, the theory $H_{0}$ was rejected and $H_{1}$ must be accepted. This is because the significance value shows the values lower than 0.05 of the significance level which are $0.000,0.049$ and 0.001 for distances $(D)$, speed $(V)$ and reaction time $(R T)$, respectively. Hence, the standard error coefficient for the constant was 1.032 , reaction time $(R T)$ the value was 0.037 and for the speed $(V)$ the standard error was 0.424 . The theory 
Table 1 Descriptive analysis for distance, speed and reaction time data.

\begin{tabular}{lllll}
\hline Case & Types & Distances & Speed & Reaction time \\
\hline Number of sample $(N)$ & Statistic & 80 & 80 & 80 \\
Mean & Statistic & 16.467 & 6.416 & 2.480 \\
& Std. error & 0.173 & 0.506 & 0.045 \\
Median & Statistic & 16.733 & 6.932 & 2.433 \\
Mode & Statistic & 14.800 & -2.542 & 2.433 \\
Std. deviation & Statistic & 1.550 & 4.527 & 0.399 \\
Variance & Statistic & 2.403 & 20.490 & 0.159 \\
Skewness & Statistic & -0.130 & -0.401 & 0.556 \\
& Std. error & 0.269 & 0.269 & 0.269 \\
Kurtosis & Statistic & -0.999 & -0.059 & -0.307 \\
Range & Std. error & 0.532 & 0.532 & 0.532 \\
Minimum & Statistic & 5.930 & 16.522 & 1.566 \\
Maximum & Statistic & 13.600 & -2.542 & 1.867 \\
Sum & Statistic & 19.530 & 13.980 & 3.433 \\
\hline
\end{tabular}

Table 2 ANOVA for final model $D_{A M V U T}$.

\begin{tabular}{llllll}
\hline Model & Sum of squares & df & Mean square & F & Sig. \\
\hline Regression & 26.477 & 2 & 13.238 & 6.240 & 0.003 \\
Residual error & 163.364 & 77 & 2.122 & - & - \\
Total & 189.841 & 79 & - & - & - \\
\hline
\end{tabular}

Table 3 Regression analysis for final model for estimating $D_{A M V U T}$.

\begin{tabular}{llllll}
\hline \multirow{2}{*}{ Predictor } & \multicolumn{2}{c}{ Unstandardized coefficients } & \multicolumn{2}{c}{ Standardized coefficients } & S F \\
\cline { 2 - 6 } & $\mathrm{B}$ & Std. error & Beta & 13.035 & 0.000 \\
\hline Constant & 13.448 & 1.032 & - & -1.998 & 0.049 \\
Speed $(V)$ & -0.075 & 0.037 & -0.218 & 3.323 & 0.001 \\
$R T$ & 1.410 & 0.424 & 0.363 & 23 & \\
\hline
\end{tabular}

for the final model estimate $D_{A M V U T}$ model can be declared as:

- $H_{0}=$ the independent variable cannot be used for predicting in the $D_{A M V U T}$ model;

- $H_{1}=$ the independent variable can be used for predicting in the $D_{A M V U T}$ model.

Fig. 4 depicts that the residual of $D_{A M V U T}$ model is normally distributed. As the point forms the like rectangular shape. Fig. 5 shows the normal probability plot of Kolmogorov-Smirnov. The graph shows the points more less fall to the line. From the P-value of Kolmogorov-Smirnov, it shows that the values are greater than 0.15 which is 0.200 . Therefore, the residual is close to normal distribution using the hypothesis:

- $H_{0}=$ the residual is not normally distributed;

- $H_{1}=$ the residual is normally distributed.

Moreover, Fig. 6 shows the normal probability plot of Shapiro-Wilk. The graph also shows the points more less fall to the line. From the $P$-value of Shapiro-Wilk, it shows that the values are greater than 0.15 which is 0.355 . According to the test, the normality assumptions cannot be rejected at the $5 \%$ level of significance. Therefore, the residual is normally distributed based on the hypothesis:

- $H_{0}=$ the residual is not normally distributed;

- $H_{1}=$ the residual is normally distributed. 


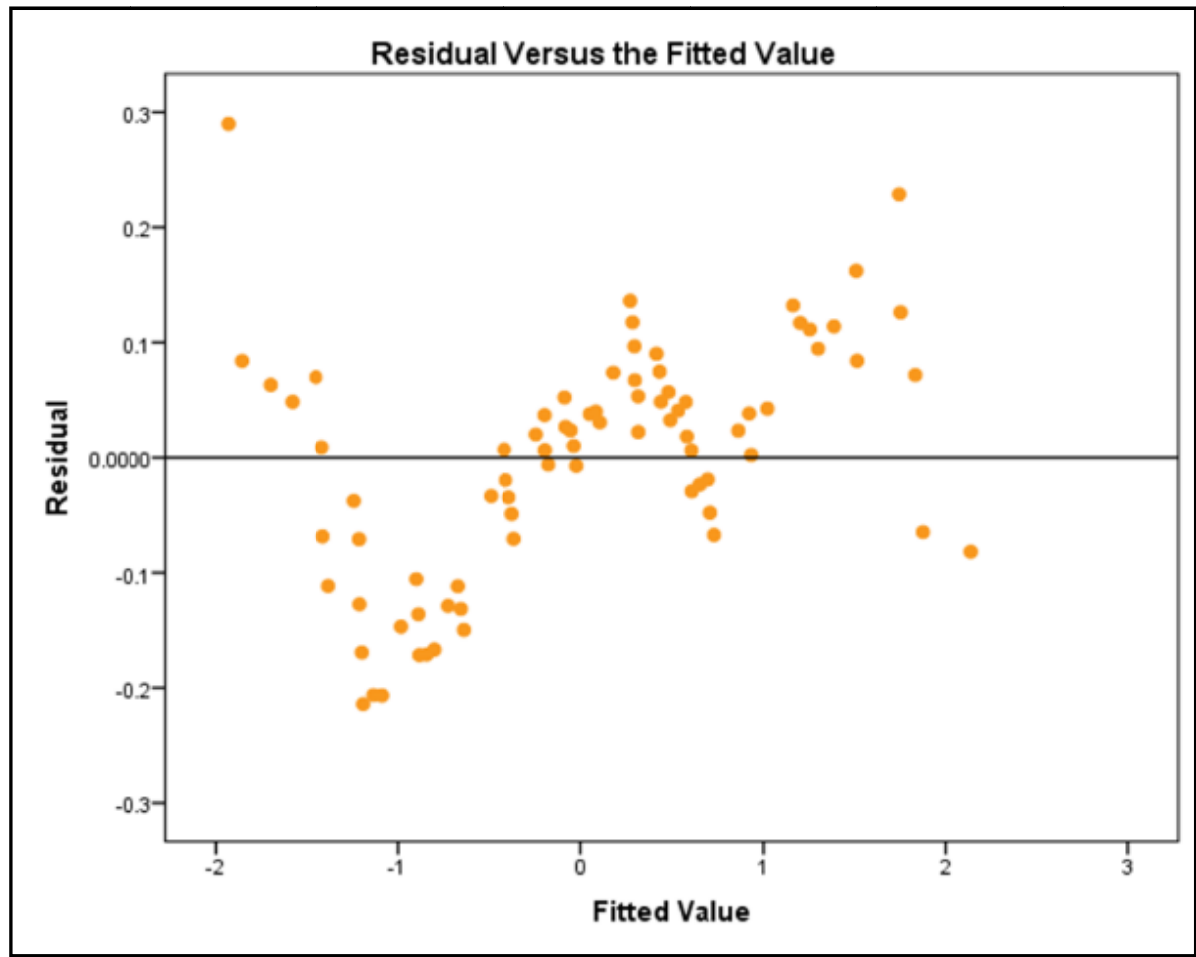

Fig. 4 Residual versus fitted values for $D_{A M V U T}$ model.

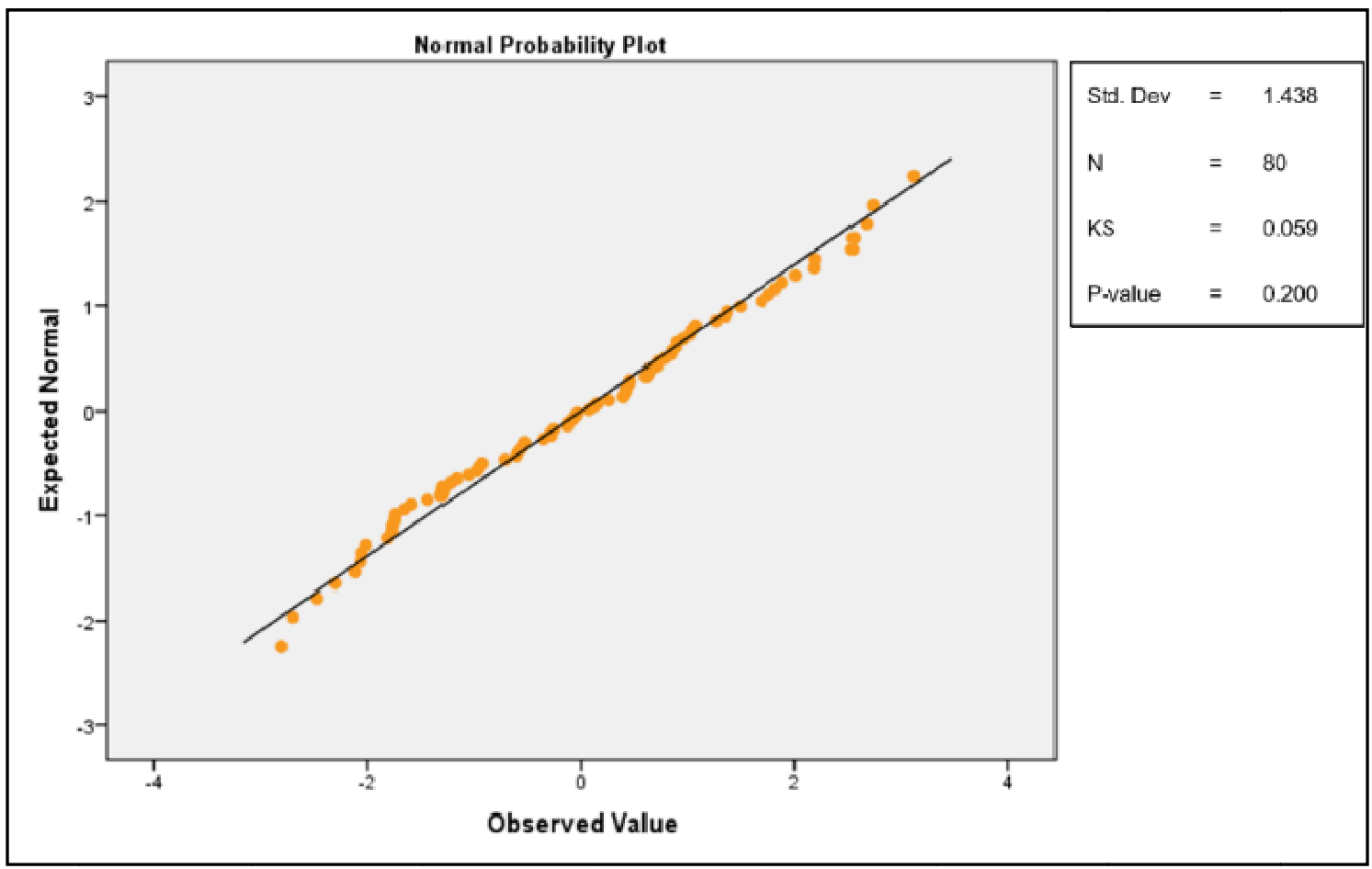

Fig. 5 Kolmogorov-Smirnov normal probability plot of residual for $D_{A M V U T}$ model. 


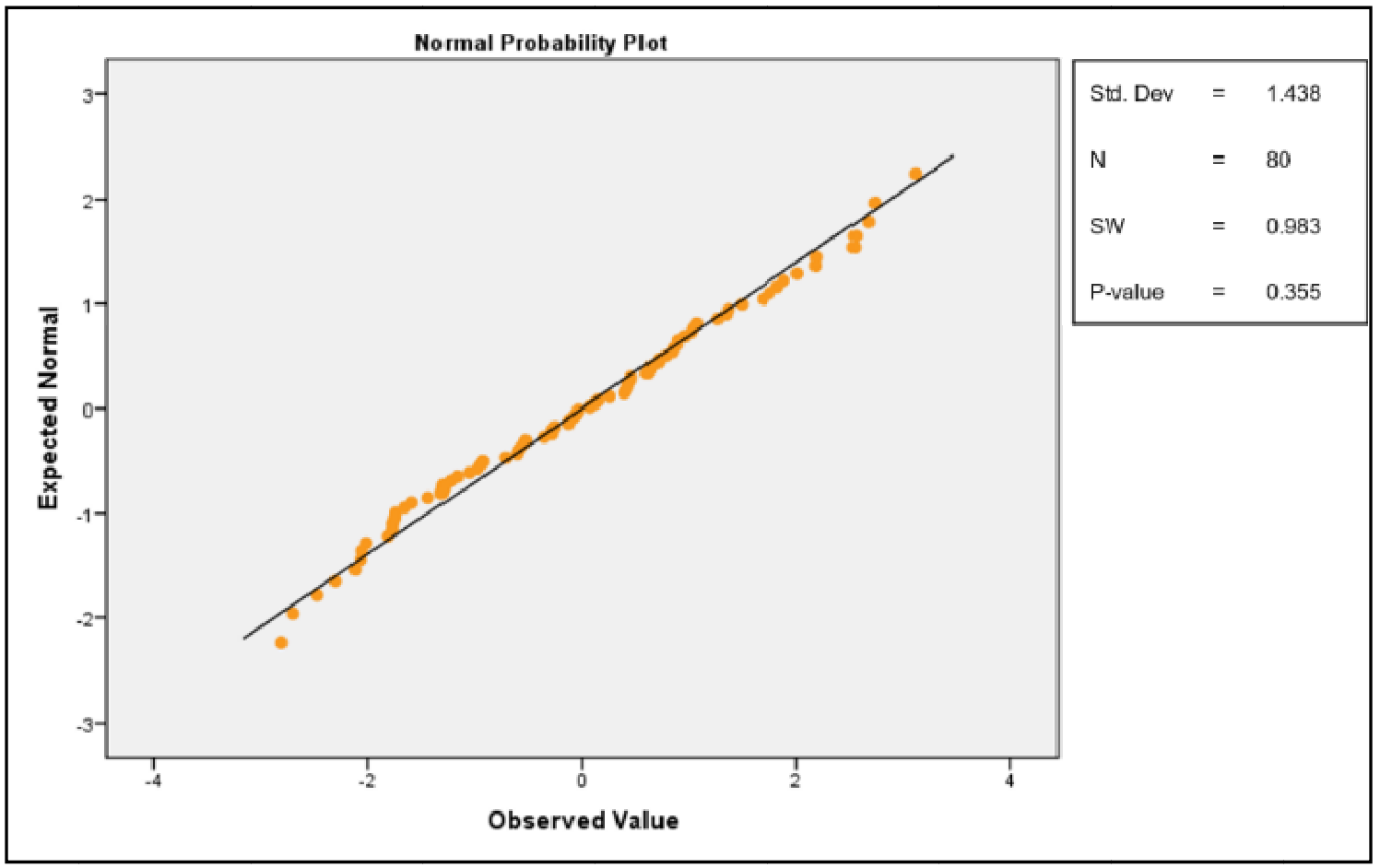

Fig. 6 Shapiro-Wilk normal probability plot of residual for $D_{A M V U T}$ model.

\section{Conclusion}

The conflicts occurred after vehicles making the U-turn, they need to merge into the main lane which is the fast lane. Therefore, vehicles in the fast lane need to response which are making the lane changing to the slow lane. This research used the data from the behavior of the driver which is speed, reaction time and the distance in executing the lane changing. By using the data, models have been developed by using the statistical analysis.

The model developed had follow all the procedure and process that is compulsory in order to make it valid. Variance analysis came out with the $P$-value where the value less than the $\alpha$-level of 0.05 where $F(2,77)=$ $6.240, p=0.003$. Hence, the regression model that has been developed is significant and thus can explain the $D_{A M V U T}$ model. The equation model developed using statistical analysis is $D_{A M V U T}=(13.448+1.410 R T-$ $0.075 \mathrm{~V}$ ). Other than that, the normal probability plot used the Kolmogorov-Smirnov and Shapiro-Wilk. The graph shows the points more less fall to the line. From the $P$-value of Kolmogorov-Smirnov, it shows the values are greater than 0.15 which is 0.200 and the same goes to Shapiro-Wilk as the value are greater than 0.15 which is 0.355 . Therefore, the residual is normally distributed and the models are valid that can be useful for the driver and traffic.

\section{Acknowledgments}

This research is supported by the Short Term Grant (STG) of UniversitiTun Hussein Onn Malaysia (UTHM) in Vot U341.

\section{References}

[1] Rahman, R. 2012. "Extent of Traffic Kinematic Waves and Queuing Caused by Midblock U-Turn Facilities." In Proceedings of the ITRN2012.

[2] Nemmang, M. S., Rahman, R, Rohani, M. M., and Mashros, N. 2017. "Analysis of Speeding Behaviour during Approaching the U-Turn Facility Road Segment Based on Driving Simulation Test." MATEC Web of Conferences 8008 (103): 1-6.

[3] Leitão, M. J., Moreira, A., Santos, J. A., Sousa, A. A., and Ferreira, F. N. 1999. "Evaluation of Driving Education Methods in a Driving Simulator." GVE'99 Computer Graphics and Visulalization Education '99, 153-8.

[4] Md Diah, J., Abdul-Rahman, M. Y., Adnan, M. A., and Atan, I. 2010. "Weaving Section Flow Model at the 
Weaving Area of Malaysian Conventional Roundabout." Journal of Transportation Engineering 136 (8): 782-92.

[5] Md Diah, J., Abdul-Rahman, M. Y., Adnan, M. A., and Hooi-Ling, K. 2011. "Modeling the Relationship between Geometric Design and Weaving Section Flow Process of Conventional Roundabouts." Journal of Transportation Engineering 137 (12): 980-6.

[6] Zhao, D., Peng, H., and Nobukawa, K. 2014. "Analysis of Mandatory and Discretionary Lane Change Behaviors for Heavy Trucks." AVEC, 355-60.

[7] Moridpour, S., Rose, G., and Sarvi, M. 2010. "Effect of Surrounding Traffic Characteristics on Lane Changing Behavior." Journal of Transportation Engineering 136 (11): 973-85.

[8] Keyvan-Ekbatani, M., Knoop, V. L., and Daamen, W.
2015. "Categorization of the Lane Change Decision Process on Freeways." Transportation Research Part C: Emerging Technologies 69: 512.

[9] Zheng, Z., Ahn, S., Chen, D., and Laval, J. 2013. "The Effects of Lane-Changing on the Immediate Follower: Anticipation, Relaxation, and Change in Driver Characteristics." Transportation Research Part C: Emerging Technologies 26: 367-79.

[10] Lv, W., Song, W. G., and Fang, Z. M. 2011. "Three-Lane Changing Behaviour Simulation Using a Modified Optimal Velocity Model.” Physica A 390 (12): 2303-14.

[11] Benedetto, A., Calvi, A., and D'Amico, F. 2011. "Effects of Mobile Telephone Tasks on Driving Performance: A Driving Simulator Study." Advances in Transportation Studies 26: 29-44. 